(C2006 IEEE. Personal use of this material is permitted. However, permission to reprint/republish this material for advertising or promotional purposes or for creating new collective works for resale or redistribution to servers or lists, or to reuse any copyrighted component of this work in other works must be obtained from the IEEE. 


\title{
AUTOMATIC GENERATION CONTROLLER IN A CHIP
}

\author{
Kukuh Karnanto \\ Syed Islam \\ Cesar Ortega-Sanchez
}

\author{
Electrical and Computer Engineering Department \\ Curtin University of Technology \\ Perth - Western Australia \\ s.islam@ece.curtin.edu.au
}

\begin{abstract}
In a power network where more than one generator is used to supply a load, power generators have to be controlled with the lowest power production cost. Network load in a power system is always varying with occasional demand surges. Even small surges create a frequency deviation in the power system and if the frequency deviation is not rapidly eliminated, the power system frequency can become unstable, causing damage to its components. One of the control methods is Automatic Generation Control (AGC). The AGC objective is to provide a power control input to each generating unit. This paper presents the implementation of an AGC strategy in a Field Programmable Gate Array (FPGA). For testing, the power generating units and the load were simulated using LabVIEW.
\end{abstract}

\section{INTRODUCTION}

Power system operation has to be stable when supplying a varying load demand[1]. The power system has to be controlled to produce power efficiently. One method is known as Automatic
Generation Control (AGC) [2]. Study of the AGC has taken place in countries as diverse as South Africa [3] ,Nigeria [4] and the United States[5]. The AGC method has been enhanced continuously. The reason is to increase the power system efficiency significantly.

Figure 1 shows the power system control diagram. It shows that the power system has a load and a control block diagram. The good communication between them is crucial to have a good control. The control block controls several generating units; furthermore, the generating units have to have unit commitment to each other. Thus, the power system power production is sufficient but yet still efficient. In this paper, the number of generating units is limited to 5. All of the generating units are thermal unit and each of them has different characteristics.

On section 2, the paper will discuss the problem of power system load variation. It explains the load variation effect on the power system. Section 2 will discuss the solution and implementation of the power system problem. The last chapter presents conclusions and future work.

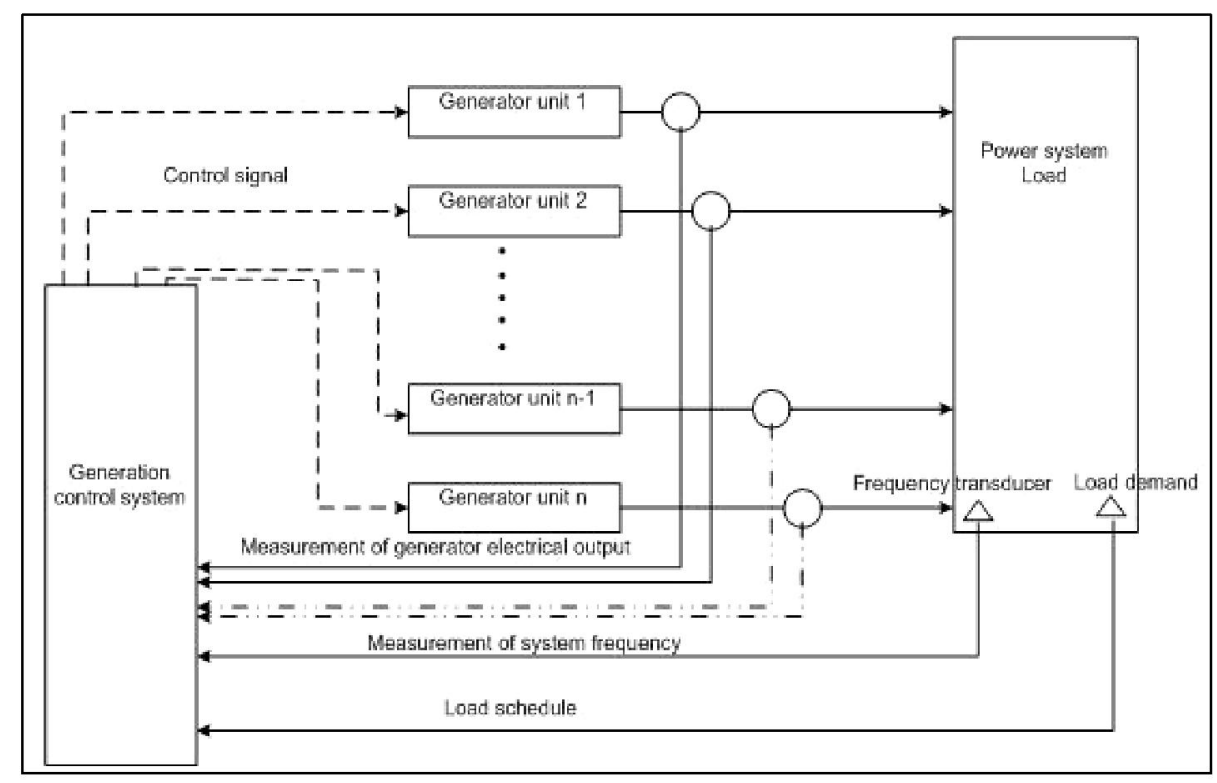

Figure 1. Power system control diagram 


\section{PROBLEM BACKGROUND}

The load has two components: a scheduled load with a 24-hour periodic behaviour, and stochastic surges. The surge load is the difference between the actual load and the schedule load. The surge load affects the power production demand and the frequency deviation affects the power system stability. The block diagram on figure 2 shows a model of how the surge load $\left(\Delta P_{R E F}\right)$ affects the frequency $(\Delta \omega)$.

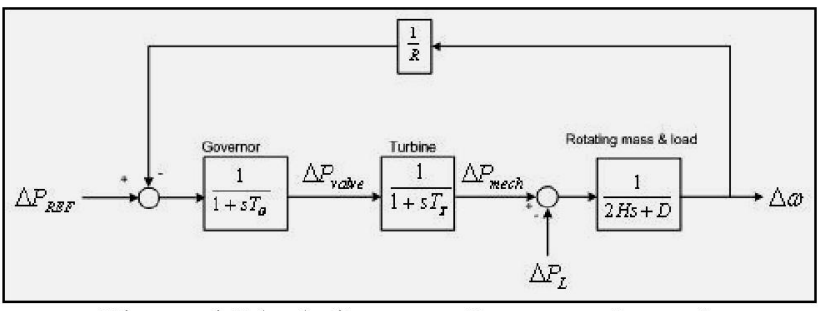

Figure 1 Block diagram of a generating unit

In Figure 2:

$\mathrm{T}_{\mathrm{G}}$ is time constant of governor

$\mathrm{T}_{\mathrm{T}}$ is time constant of turbine

$\mathrm{H}$ is constant value of inertia, which is the change of

kinetic energy over the machine rating

$\mathrm{D}$ is expressed as percent change in load divided by percent change in frequency

$\mathrm{R}$ is constant of speed regulation

When the load changes, the generating units need to be controlled for cost efficiency. In other words, the function of the controller is to distribute the current load between the generators, in such a way that the cost of fuel is minimised. On high peak load, all the generating units have to be working regardless their efficiency. However on medium and low demands, the most efficient generating units must have higher priority to be active[6]. In this paper 5 units will be considered. Table 1 shows their characteristics.

Table 1: The generating units' characteristics

\begin{tabular}{||c|c|c|c||}
\hline Unit & $\begin{array}{c}\text { Minimum } \\
\text { production } \\
\text { (MW) }\end{array}$ & $\begin{array}{c}\text { Maximum } \\
\text { production } \\
\text { (MW) }\end{array}$ & $\begin{array}{c}\text { Fuel cost } \\
\text { (\$/MBtu) }\end{array}$ \\
\hline Unit 1 & 150 & 550 & 1.1 \\
\hline Unit 2 & 200 & 450 & 0.9 \\
\hline Unit 3 & 150 & 600 & 1.2 \\
\hline Unit 4 & 100 & 400 & 1.0 \\
\hline Unit 5 & 50 & 200 & 0.8 \\
\hline \hline
\end{tabular}

\section{DESIGN AND IMPLEMENTATION}

Unit commitment on economic dispatch was chosen as the AGC method. The AGC was implemented as an embedded system using an FPGA by Xilinx. LabVIEW was used to simulate the power system generating unit and the load simulation. Figure 3 shows the main components of the system.

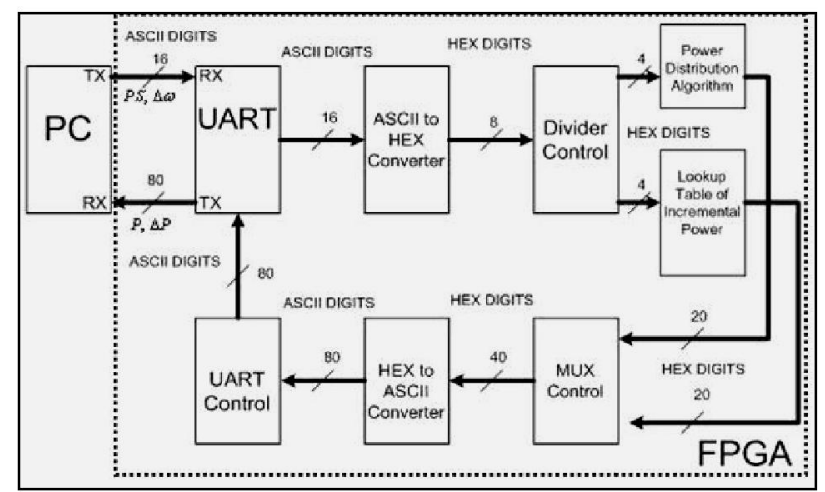

Figure 2 Block diagram control of FPGA

FPGAs allow the design of custom integrated circuits. FPGA implementations are faster and more reliable than software execution. Furthermore, the FPGA design can be used for IC development in the future [7]. One advantage of FPGAs is they fully integrate a scalable design platform that is Silicon and Vendor-independent. This independence is achieved by describing designs in VHDL (Very High Speed Integrated Circuit Hardware Description Language)[8]. FPGAs have been responsible for a major shift in the way digital circuits are designed [9].

LabVIEW is a graphical software environment to customize or design a particular hardware instrument inside a PC [10]. This particular software has ability for simulation, data capture, data analysis, and circuit animation. When a particular application has been built, the LabVIEW program's output is a virtual instrument (VI). The VI has two main components, which are front panel and block diagram. The front panel of the VI used to test the system presented in this paper is shown in Figure 4.

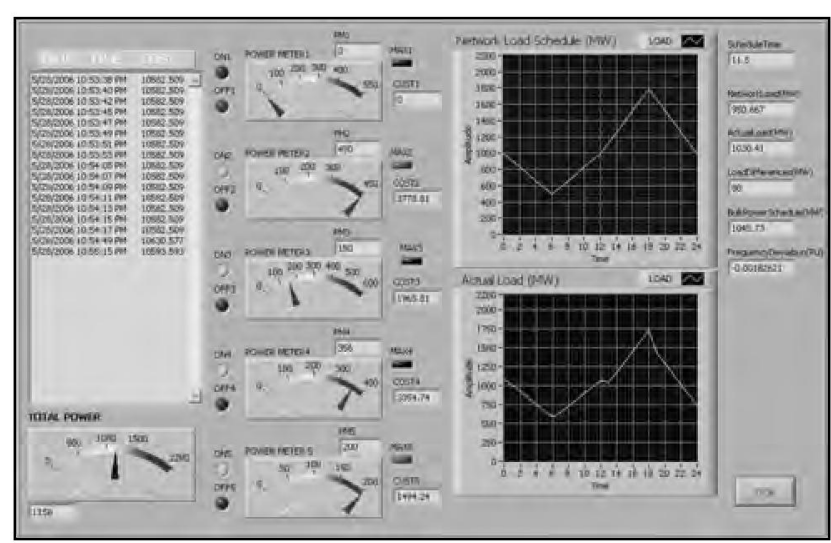

Figure 3. Front panel of user interface

\subsection{Unit Commitment for Load Variation}

In Figure 3, the power distribution algorithm block is defined based on unit commitment. To achieve this, the cost characteristic for each generating units has to be defined. The equations for the units' inputoutput characteristic and fuel cost are: 


\section{Unit 1}

$\mathrm{H}_{1}(\mathrm{MBtu} / \mathrm{H})=515+9.3 \mathrm{P}_{1}+0.00153 \mathrm{P}_{1}^{2}$

Fuel Cost $_{1}=1.1 \$ / \mathrm{MBtu}$

$\mathrm{F}_{1}\left(\mathrm{P}_{1}\right)=\mathrm{H}_{1} \times \mathrm{FC}_{1}=566.5+10.23 \mathrm{P}_{1}+1.683 \times 10-3 \mathrm{P}_{1}^{2} \$ / \mathrm{h}$

$$
\frac{d F_{1}}{d P_{1}}=10.23+3.366 \times 10^{-3} P_{1}=\lambda
$$

\section{Unit 2}

$\mathrm{H}_{2}(\mathrm{MBtu} / \mathrm{H})=355+7.7 \mathrm{P}_{2}+0.00187 \mathrm{P}_{2}^{2}$

Fuel Cost ${ }_{2}=0.9 \$ / \mathrm{MBtu}$

$$
\begin{gathered}
\mathrm{F}_{2}\left(\mathrm{P}_{2}\right)=\mathrm{H}_{2} \times \mathrm{FC}_{2}=319.5+6.93 \mathrm{P}_{2}+1.683 \times 10-3 \mathrm{P}_{2}^{2} \$ / \mathrm{h} \\
\frac{d F_{2}}{d P_{2}}=6.93+3.366 \times 10^{-3} P_{2}=\lambda
\end{gathered}
$$

\section{Unit 3}

$$
\mathrm{H}_{3}(\mathrm{MBtu} / \mathrm{H})=511+7.3 \mathrm{P}_{3}+0.00143 \mathrm{P}_{3}{ }^{2}
$$

Fuel Cost $_{3}=1.2 \$ / \mathrm{Mbtu}$

$$
\begin{gathered}
\mathrm{F}_{3}\left(\mathrm{P}_{3}\right)=\mathrm{H}_{3} \times \mathrm{FC}_{3}=613.2+8.76 \mathrm{P}_{3}+1.716 \times 10-3 \mathrm{P}_{3}^{2} \mathrm{~S} / \mathrm{h} \\
\frac{d F_{3}}{d P_{3}}=8.76+3.432 \times 10^{-3} P_{3}=\lambda
\end{gathered}
$$

\section{Unit 4}

$\mathbf{H}_{4}(\mathrm{MBtu} / \mathrm{H})=313+7.85 \mathrm{P}_{4}+0.00195 \mathrm{P}_{4}{ }^{2}$

Fuel Cost $_{4}=1.0 \$ / \mathrm{Mbtu}$

$$
\begin{gathered}
\mathrm{F}_{4}\left(\mathrm{P}_{4}\right)=\mathrm{H}_{4} \times \mathrm{FC}_{4}=313+7.85 \mathrm{P}_{4}+1.95 \times 10-3 \mathrm{P}_{4}^{2} \$ / \mathrm{h} \\
\frac{d F_{4}}{d P_{4}}=7.85+3.9 \times 10^{-3} P_{4}=\lambda
\end{gathered}
$$

\section{Unit 5}

$\mathrm{H}_{5}(\mathrm{MBtu} / \mathrm{H})=79.0+7.97 \mathrm{P}_{5}+0.00487 \mathrm{P}_{5}^{2}$

Fuel Cost $_{5}=0.8 \$ / \mathrm{Mbtu}$

$$
\begin{gathered}
\mathrm{F}_{5}\left(\mathrm{P}_{5}\right)=\mathrm{H}_{5} \times \mathrm{FC}_{5}=63.2+6.376 \mathrm{P}_{5}+3.896 \times 10-3 \mathrm{P}_{5}^{2} \$ / \mathrm{h} \\
\frac{d F_{5}}{d P_{5}}=6.376+7.792 \times 10^{-3} P_{5}=\lambda
\end{gathered}
$$

Where:

$F$ is fuel cost

$P$ is power production

The gradient of fuel cost based on power production ( $\lambda$ ) shows the rate of fuel consumption [11]. To have an optimum power production is to find a $\lambda$ equal for all generating units, taking into account the constraints of minimum and maximum power production. Furthermore, $\lambda$ also defines which generating unit has better efficiency. Equations (1) to (5) show that the list of generating units ordered by efficiency is $5,2,4,3$, and 1 . For instance, generating unit number 5 will be operating before unit number 2 . This priority method is defined the value of $P_{i}$ (where $i$ is the number of generating unit).

\subsection{Integral Control for Frequency Deviation}

The frequency deviation is removed from the system using an integral control[12]. Integral control uses a feedback of the frequency deviation and a load reference to adjust the governor. The block diagram of the integral control can be seen in figure 5 .

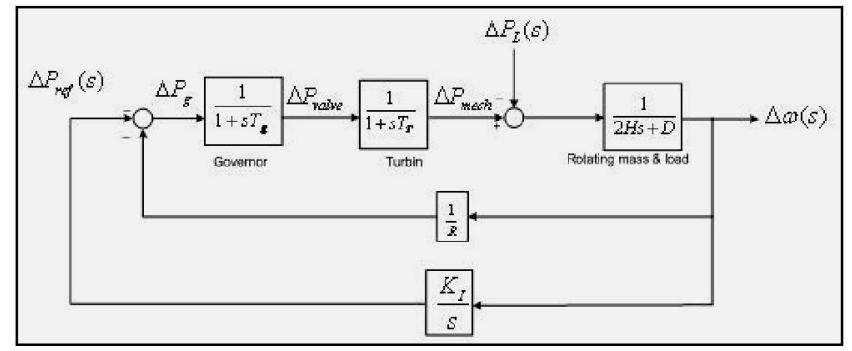

Figure 4 An integral control on a generating unit

The closed loop transfer function of the control system shown in figure 5 with only $\Delta \mathrm{P}_{\mathrm{L}}$ as input becomes:

$\frac{\Delta \omega}{-\Delta P_{L}}=\frac{s^{3}\left(T_{T} T_{g}\right)+s^{2}\left(T_{T}+T_{g}\right)+s}{s^{4}\left(2 H T_{T} T_{g}\right)+S^{3}\left(2 H\left(T_{T}+T_{g}\right)+D\left(T_{T} T_{g}\right)\right)+s^{2}\left(2 H+D\left(T_{T}+T_{g}\right)\right)+s\left(D+\frac{1}{R}\right)+K_{I}}$

By applying the Routh stability criterion [13], the range of $K_{I}$ that keeps the system stable is obtained. The values of $K_{I}$ obtained for the units used in this paper are shown in table 3 .

Table 2: Minimum and maximum of integral gain $\left(\mathrm{K}_{\mathrm{I}}\right)$

\begin{tabular}{||c||c|c||}
\hline \hline Unit number & Min $\mathrm{K}_{\mathrm{I}}$ & Max K $_{\mathrm{I}}$ \\
\hline Unit 1 & 0 & 10.721 \\
\hline Unit 2 & 0 & 6.233 \\
\hline Unit 3 & 0 & 2.128 \\
\hline Unit 4 & 0 & 3.582 \\
\hline Unit 5 & 0 & 6.121 \\
\hline
\end{tabular}

From all possible values of $\mathrm{K}_{\mathrm{I}}$, the value that produces the fastest settling time has to be chosen. To find these values, the step 0.125 method was used within the allowable range. Result can be seen in the table 4.

Table 3: Optimal values for $\mathrm{K}_{\mathrm{I}}$

\begin{tabular}{||c|c|}
\hline & $\mathrm{K}_{\mathrm{I}}$ \\
\hline Unit 1 & 1.875 \\
\hline Unit 2 & 2.187 \\
\hline Unit 3 & 2.128 \\
\hline Unit 4 & 1.812 \\
\hline Unit 5 & 1.5 \\
\hline
\end{tabular}




\subsection{Look Up Table for Incremental Power}

The incremental power is used to correct the power production according to the surge load demand. On this paper, a look up table (LUT) has been created to manage the incremental power. The LUT is defined from the steady state frequency deviation of the power system.

$$
\Delta \omega_{s s}=\frac{-\Delta P_{L}}{D+\frac{1}{R}}
$$

While for multi generating units, on single area, the steady state frequency deviation becomes [6]:

$$
\Delta \omega_{s s}=\frac{-\Delta P_{L}}{D+\sum_{i=1}^{n} \frac{1}{R_{i}}}
$$

Where $\mathrm{n}$ is total number of generating units.

Since the total number of generating units in this paper is five, the steady state frequency deviation becomes:

$$
\Delta \omega_{s s}=\frac{-\Delta P_{L}}{D+\frac{1}{R_{1}}+\frac{1}{R_{2}}+\frac{1}{R_{3}}+\frac{1}{R_{4}}+\frac{1}{R_{5}}}
$$

The load deviation is assumed within the range of 0.4 to -0.4 with step of 0.01 . For each load deviation value, the value of the steady state frequency deviation is determined. The LUT was created in three steps.

The first step is to find the value of steady state frequency deviation and incremental power for each unit. Because it is easier to create the LUT in integer value, thus the second step is scale the steady state frequency deviation by a factor of $10^{4}$ and the incremental power by a factor of $10^{5}$. Furthermore, a hexadecimal number will save more space rather than just decimal number. Thus the last step is to convert the number to hexadecimal. Table 5 shows the three steps as applied to unit 1 in this example.

Table 4: Lookup table creation steps

\begin{tabular}{||c|c|c|c|}
\hline \hline Step & $\Delta \mathrm{P}_{\mathrm{L}}$ & $\Delta \omega$ & $\Delta \mathrm{P}_{1}$ \\
\hline 1 & -0.4 & 0.00913096 & 0.07189733 \\
\hline 2 & -0.4 & 91 & 7189 \\
\hline 3 & -0.4 & $5 \mathrm{~B}$ & $1 \mathrm{C} 16$ \\
\hline
\end{tabular}

The LUT can now be used to determine the incremental power $\left(\Delta \mathrm{P}_{i}\right)$ of each generating unit. The final LUT was stored in a file in the $\mathrm{PC}$ and downloaded to the FPGA using a serial port.

\section{CONCLUSIONS}

The unit commitment objective is to minimize the operating cost of the power system. This unit commitment is used to distribute the appropriate power production to each generating unit.

An indicator of a load change in the system is the frequency deviation. While it can be taken as an indicator, it can be forced to zero using the integral control.

The lookup table is a simple method to define the incremental power of generating unit power production.

LabVIEW is a good tool to simulate systems. In this work it has been used to simulate the generating units' power production and the load. The interface exchange information with the FPGA using a serial communications channel.

FPGA-based AGC could be used to keep a power system stable in a fast and reliable way.

\section{REFERENCES}

[1] C. A. Gross, Power System Analysis, second ed. New York: John Wiley \& Sons, Inc, 1986.

[2] D. M. V. Kumar, "Intelligent Controllers for Automatic Generation Control," IEEE, 1998.

[3] G. A. Chown, "Design and Experience with a Fuzzy Logic Controller for Automatic Generation Control (AGC)," IEEE Transactions on Power Systems, vol. 13, pp. 965, 1998.

[4] J. Katende and N. O. Frank, "Automatic Generation Control Performance of the Nigerian Power System after Deregulation," IEEE Africon, pp. 717, 2004.

[5] J. Huang, P. Yalla, T. Yong, G. Ford, and M. Rothleder, "New Real Time Market Application at the California Independent System Operator (CAISO)," IEEE, 2004.

[6] A. J. Wood and B. F. Wollenberg, Power Generation, Operation, and Control, second ed. New york: John Wiley \& Sons, inc., 1984.

[7] FPGA tutorial, Retrieved: 08 November, 2005, from http://www.tutorial-reports.com/computerscience/fpga/

[8] J. V. d. Spiegel, VHDL tutorial, Retrieved: 08 November, 2005, from http://www.seas.upenn.edu/ ee201/vhdl/vhdl prime r.html\#_Toc526061347

[9] S. Brown and J. Rose, "Architecture of FPGAs and CPLDs: A Tutorial," Department of Electrical and Computer Engineering, University of Toronto, Toronto.

[10] N. Ertrugul, LabVIEW: For Electric Circuits, Machines, Drives, and Laboratories. New Jersey: Prentice Hall PTR, 2002.

[11] W. D. S. Jr, Elements of Power System Anaylisis, four ed. Singapore: McGraw-Hill, 1982.

[12] H. Saadat, Power System Analysis, second ed: The McGraw-Hill Companies, Inc, 2002.

[13] K. Ogata, Modern Control Engineering, Fourth ed. New Jersey: Prentice Hall, 2002. 